\title{
The Carbon Dioxide Clathrate Disposal in a Pit near Japan
}

\author{
Lucian MÂNDREA \\ Politehnica University of Bucharest, Bucharest, Romania \\ mandrea_lucian@hotmail.com,lucian.mandrea@upb.ro \\ Viorel BĂDESCU \\ Candida Oancea Institute, Politehnica University of Bucharest, Bucharest, Romania \\ badescu@theta.termo.pub.ro \\ Ionuț Cristian VOICU \\ Politehnica University of Bucharest, Bucharest, Romania \\ ionut-cristian.voicu-extern@renault.com
}

\begin{abstract}
The research purpose is to present the possibility to deposit the carbon dioxide clathrate at the ocean bottom near Japan. As it is well known, a big amount of $\mathrm{CO}_{2}$ is produced nowadays, with a very damaging influence on the climate. These effects can already be seen all around the world. A possible solution to get rid of the $\mathrm{CO}_{2}$ surpluses is to liquefy it, transform it into carbon dioxide clathrate and send it through pipes at very low levels into the oceans or seas, where its density is bigger than the salted ocean water density. Theoretical ideas are presented at the beginning. An analytical method is used to calculate the carbon dioxide clathrate pressure at the exit of the pipe and also the pressure at a certain depth into the ocean. Because the carbon dioxide clathrate density and the sea water density are variable at different depths, an integral calculus must be done. The authors also calculated the flow rate through the pipes and the time needed to deposit the clathrate at the bottom of the ocean. The volume of the pit is also determined. A particular calculus is made in the case of the Ryukyu pit near Japan. It has steep slopes and the depth reaches around 8000 meters. The location was chosen because, in the case of Japan, high amounts of $\mathrm{CO}_{2}$ are produced. Hurricanes cross this country. Therefore, we suppose that large interest can appear for such a solution to change the climate even locally. Depending on the previous parameters, one can analyze the opportunity for the practical deposition of the carbon dioxide clathrate in the respective pit with a further economical calculus. The calculus which uses the prices in Japan can estimate the cost to liquefy the $\mathrm{CO}_{2}$ and to send it to the bottom of the ocean as well as compare it with other methods to reduce the $\mathrm{CO}_{2}$ quantity in the atmosphere.
\end{abstract}

Keywords: Global warming, Carbon dioxide clathrate, Ocean pit, volumetric flow rate, Japan.

\section{Introduction}

As long as global warming is increasing, solutions must be discovered faster. During the last years, different great damaging events showed even for the skeptics that the cause of many different types of catastrophes is the global rise of the temperature. References can be found, for instance, in global reports [IEA, 2015].

The initial cause is believed to be the human activity which generates high amounts of $\mathrm{CO}_{2}$. For instance, in 2017, a total amount of $35 \mathrm{Gt}$ of $\mathrm{CO}_{2}$ was released into the atmosphere. As a consequence, attitudes appear and the major part of the Europeans considers that every citizen should do something about it. Opinions are, of course, different. The Germans who are very dedicated to the environment protection consider that the responsibility belongs both to the firms and to political decisions. Most of the Romanians consider that we all are responsible for reducing the $\mathrm{CO}_{2}$ emissions. All these opinions and the corresponding data were obtained as a result of the soundings done at the request of the E.ON Company. Of course, that each of us can take individual measures. One can use energy from renewable sources, try to improve the energy 
efficiency of the own house, recycle materials, buy an electric car, or diminish the energy consumption at the firm where they work. Most Europeans consider that it is their duty to diminish the quantity of the gas emissions that damage the atmosphere. 7200 persons from Romania, Germany, Italy, Great Britain, Sweden, Czech Republic and Hungary were interviewed in the soundings done at the request of the E.ON Company. As a result of the soundings, $42.3 \%$ of the persons consider that everybody has major responsibility. More than a third considers that investments and improvements must be made in installations and devices to reduce the amount of the $\mathrm{CO}_{2}$ released in the atmosphere. The final conclusion of the soundings done using the CAWI method (Computer Assisted Web Interviewing) in the previous seven countries was that practical examples prove that the energy production without $\mathrm{CO}_{2}$ emissions is completely possible today. Even if this could be the future tendency, the measures to reduce the amount of the $\mathrm{CO}_{2}$ released in the atmosphere must be taken today.

In this big step forward, the universities must have a major role. As a consequence, in the frame of SAM (European Scientific Advice Mechanism), many proposals were made by SAPEA (Science Advice for Policy by European Academies).

The report called "New technologies to capture and utilize the atmospheric carbon" (CCU), was made in the "Climatic Policies and Energy" domain. All the information can be found at the internet address https://www.sapea.info/ccu/.

Special reports were made as the one presented by Cambridge University Press [IPCC, 2005] or the one with the capture using water scrubbing [IEAGHG, 2000].

As some researchers showed before [Goldthorpe, 2017], [Mândrea et al., 2018], a solution to decrease the amount of $\mathrm{CO}_{2}$ in the atmosphere is to liquefy the gas and send it to the bottom of an ocean or a sea if it is deep enough. The pit chosen this time by the authors is closer to two countries which are large producers of $\mathrm{CO}_{2}$. It also has a big depth and a large capacity to store high amounts of carbon dioxide clathrate. We believe that this one is a more interesting position from the economical point of view than the previous one considered in [Mândrea et al., 2018].

There are other authors who are very preoccupied by the problem of global warming correlated with the complexity of the oceans [Gatusso et al., 2018] and with the liquid $\mathrm{CO}_{2}$ deposition on the seas and oceans bottom as we can see at https://www.greenfacts.org/en/co2-capture-storage/l-3/6-ocean-storage-co2.htm.

This interesting zone to be analyzed is situated near Japan. Some characteristics can be found at https://en.m.wikipedia.org/wiki/Ryukyu_Islands.

The authors chose for this article the location near Japan with its very deep pit called Ryukyu. It reaches a depth of almost $8000 \mathrm{~m}$, as presented in Figure 1. Details about the characteristics of the zone chosen by the authors can also be found in [Kim \& Chung, 1984], [Kim et al., 1996], [Kim et al., 2001], [Minami et al., 1997], [Miyazaki, 1953], [Senjyu \& Sudo, 1996], [Sudo, 1986] and [Yasui et al., 1967]. 


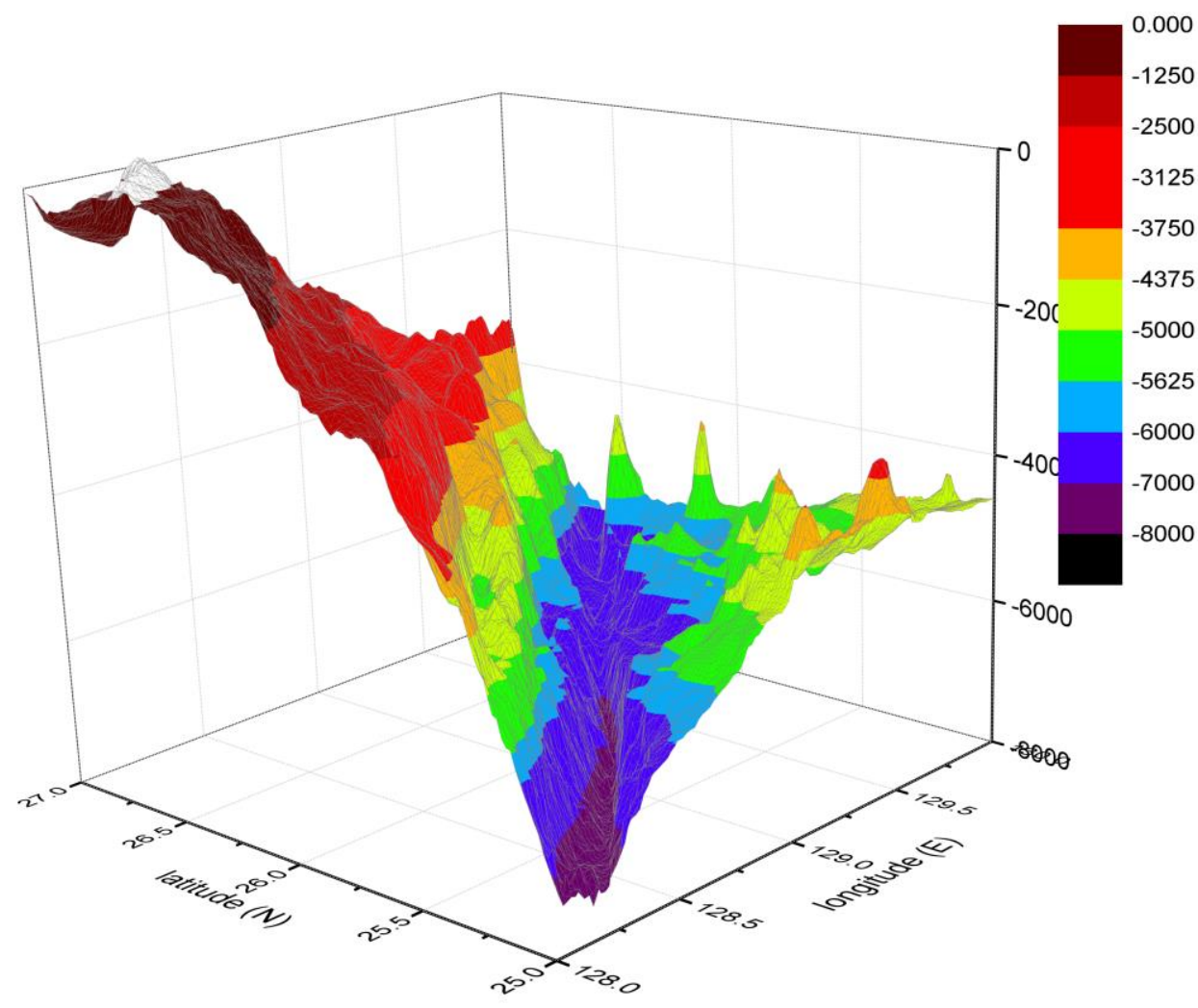

Figure 1.The Ryukyu pit near Japan with its corresponding depths

This location can be an economical one because Japan and also China are large $\mathrm{CO}_{2}$ producers. As we can notice from Figure 1, the zone taken into consideration by the authors with the depth bigger than $4375 \mathrm{~m}$ is placed between $128^{\circ}$ and $130^{\circ}$ longitude and between $25^{\circ}$ and $27^{\circ}$ latitude.

The surface between $129^{\circ}$ and $130^{\circ}$ longitude and between $25^{\circ}$ and $26^{\circ}$ latitude is shown in Figure 2. The image also contains the perimeter zone and the surface area.

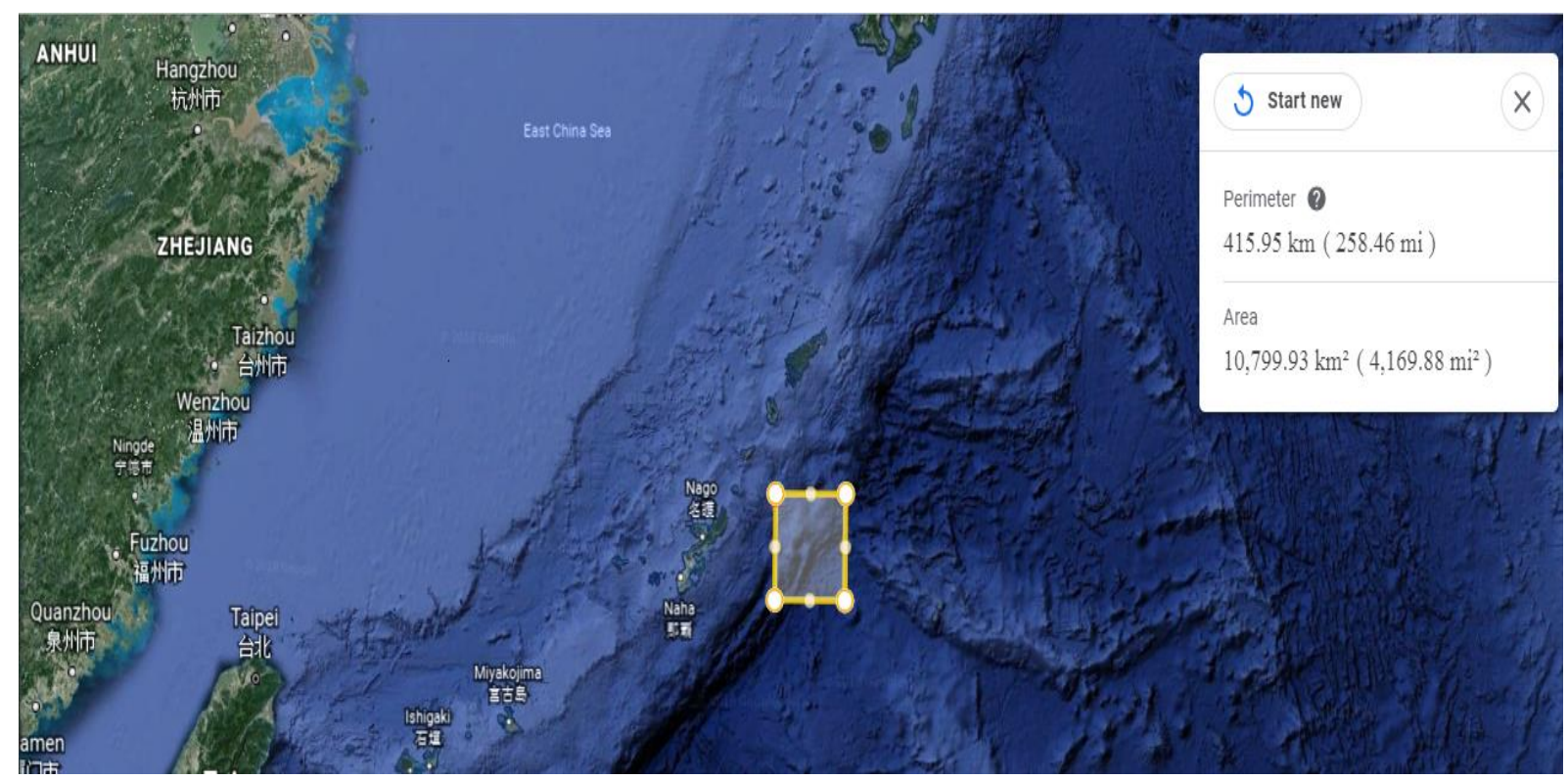

Figure 2.The Ryukyu pit seen on Google Earth [Google Earth software] 


\section{Theoretical approaches}

The liquid $\mathrm{CO}_{2}$, transformed into carbon dioxide clathrate, is transported by a pump and then sent through a pipe to the bottom of the ocean Ryukyu pit. We need to know the carbon dioxide clathrate volumetric flow rate to calculate the necessary time to fill the pit. To obtain the volumetric flow rate we must first determine the available volume situated under $4375 \mathrm{~m}$, using the data from Figure 1.

An extended table of the data in Excel was used to obtain a mean depth of the useful depth, which was later employed to get the volume which will be filled with the amount of the carbon dioxide clathrate. The mean depth of the useful zone will be computed as an arithmetic mean of the useful depth values corresponding with Figure 1.

The characteristics of the ocean water in the Ryukyu pit are presented in Figure 3 [Kawamura et al., 2007].

(a)

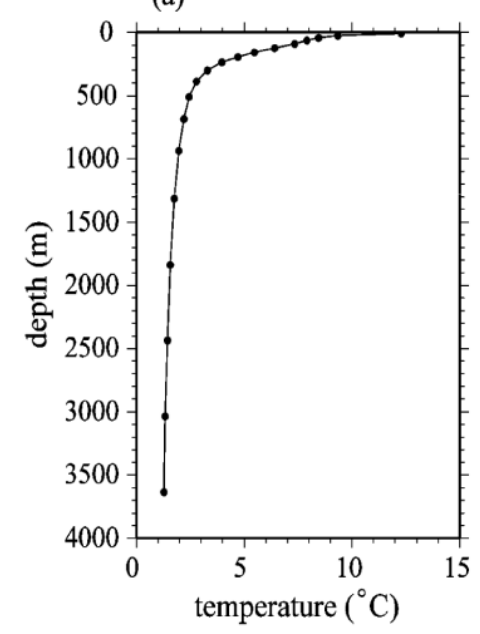

(b)

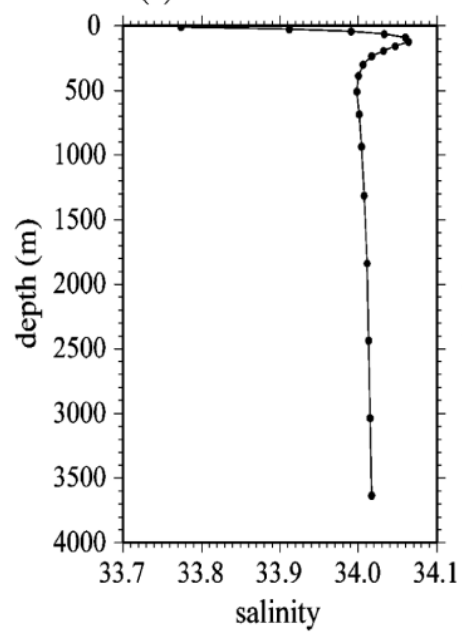

(c)

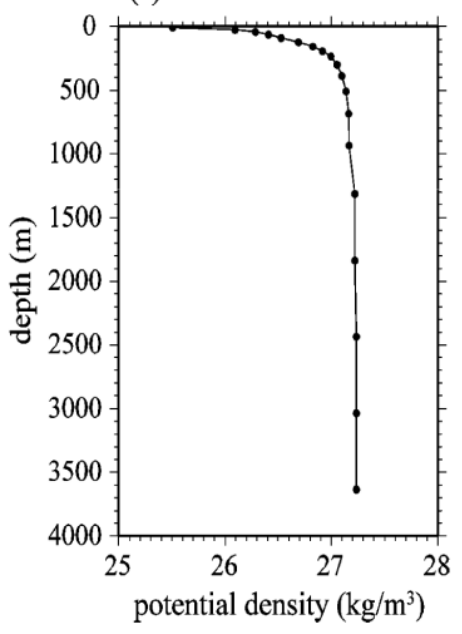

Figure 3.The mean temperature, salinity and potential density of the ocean water inside the Ryukyu pit [Kawamura et al., 2007].

As we can see in Figure 3, there are two zones near the ocean surface where the salinity varies a lot and, then, a deeper zone with almost the same salinity. Three zones with different density will be considered in the next calculus, as in Figure 4.

In principle, every density varies continuously with the depth, with the temperature and also with the salinity at that depth.

Using the formula of a liquid column pressure [Mândrea, 2008], [Florea \& Panaitescu, 1979], the carbon dioxide clathrate pressure at the exit of the pipe from Figure 4 is:

$$
p_{\text {pipe }, 2}=\int_{0}^{H} \rho_{\mathrm{CO}_{2}}\left(t^{\circ}(z)\right) \cdot g(z) \cdot d z
$$

In this formula, the depth $\mathrm{H}$ represents the depth to the end of the pipe, where the carbon dioxide clathrate is inserted in the ocean water.

The pressure of the ocean water at the level of the pipe exit is:

$$
p_{\text {ext }, 2}=\int_{0}^{h_{s}} \rho_{s}\left(t^{\circ}(z)\right) \cdot g(z) \cdot d z+\int_{h_{s}}^{h_{s}+h_{m}} \rho_{m}\left(t^{\circ}(z)\right) \cdot g(z) \cdot d z+\int_{h_{s}+h_{m}}^{H} \rho_{b}\left(t^{\circ}(z)\right) \cdot g(z) \cdot d z
$$

The pressure difference between the carbon dioxide clathrate pressure at the exit of the pipe and the pressure of the ocean water at the level of the pipe exit is:

$$
\Delta p=p_{\text {pipe }, 2}-p_{\text {ext }, 2}
$$

Since the pipe is very long, usually hundreds of meters, we can consider that all the local hydraulic losses can be neglected. 


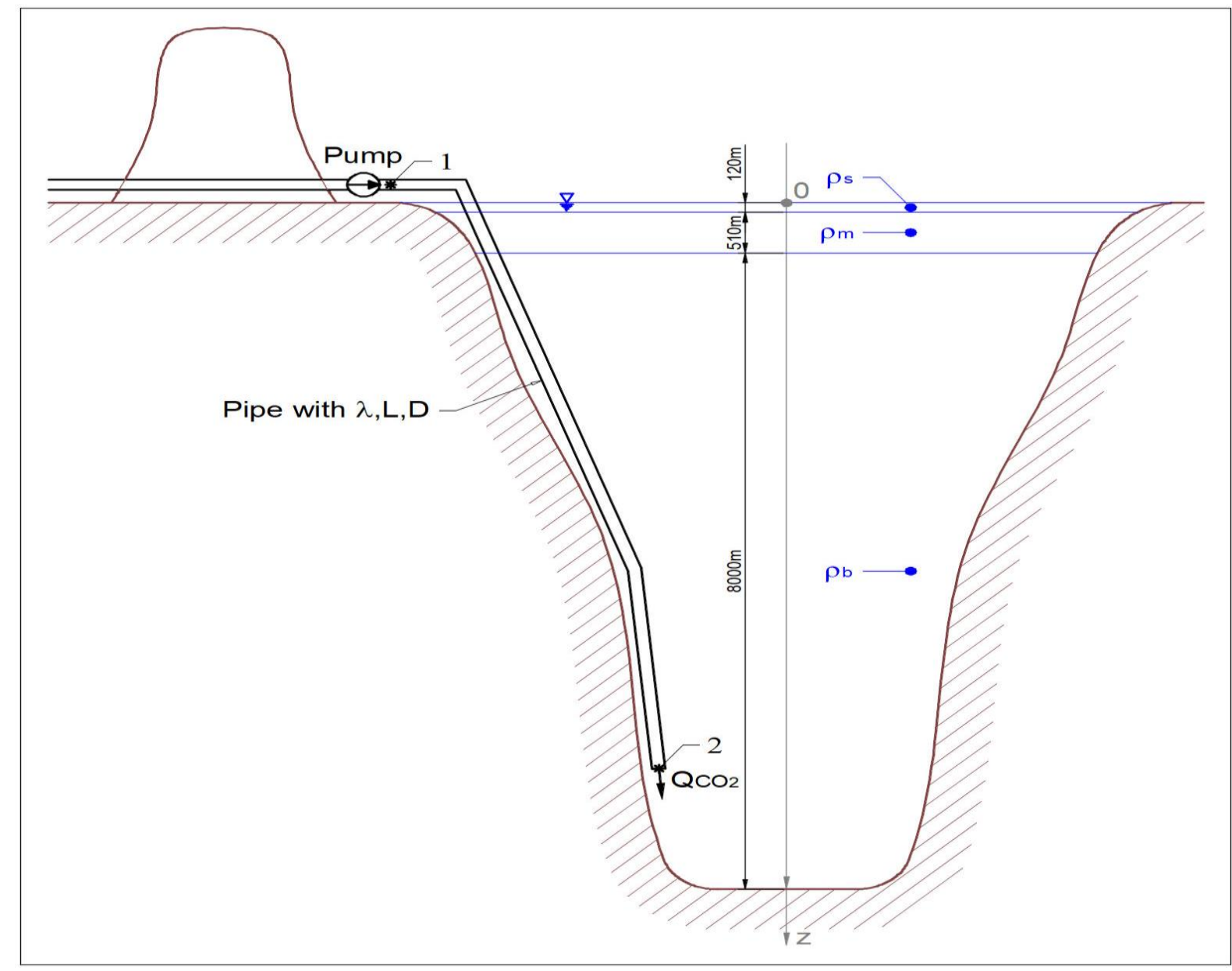

PICBE | 292

Figure 4.The Ryukyu pit to be filled with carbon dioxide clathrate at the ocean bottom

The energy of the pressure difference is then consumed on the linear hydraulic losses along the pipe and the rest is transformed into kinetic energy, as in:

$$
\Delta p=\frac{\rho_{\mathrm{CO}_{2}} v_{2}^{2}}{2}+\lambda \frac{L}{D} \frac{\rho_{\mathrm{CO}_{2}} v_{2}^{2}}{2}
$$

The carbon dioxide clathrate mean speed at the exit of the pipe is obtained:

$$
v_{2}=\sqrt{2 \frac{\Delta p}{\rho_{\mathrm{CO}_{2}}\left(1+\lambda \frac{L}{D}\right)}}
$$

Since we suppose that the pump works continuously, we can consider that the carbon dioxide clathrate movement is permanent. The simplified formula for the volumetric carbon dioxide clathrate rate flow from the kinematics of the fluids can then be applied.

We can express then the volumetric carbon dioxide clathrate rate flows by two well-known formulas from the fluid kinematics:

$$
Q=\frac{\pi D^{2}}{4} v_{2}=\frac{V}{T}
$$

The necessary time to fill the ocean pit with carbon dioxide clathrate is, then:

$$
T=\frac{V}{Q}
$$


A second option for the exit of the pipe can be taken into account. The pipe can reach the bottom of the ocean and in this case the linear hydraulic losses will increase. The calculus will become more complicated, because the depth of the carbon dioxide clathrate situated over the pipe exit will vary. Also, the depth of the last layer of salty water will vary. Another integral calculus should then be applied. This second technical option could be analyzed at the beneficiary's desire since it requires more computations.

A similar hydraulic calculus but referring at desalinization can be found in [Badescu et al., 2012].

\section{Calculus example}

The value of the ocean depth under which we shall deposit the carbon dioxide clathrate that we have considered is of $4375 \mathrm{~m}$ and is presented with yellow-green colors in Figure 1. This depth assures us that even if the global temperature will rise a little, the carbon dioxide clathrate will remain liquid. The maximum depth of the pit is of $7671 \mathrm{~m}$, almost $8000 \mathrm{~m}$.

Considering the variations of the mean temperature, salinity and potential density of the ocean water from Figure 3, three values were calculated for the ocean water density. They were obtained as mean arithmetic density values for the three vertical zones presented on the vertical odds in Figure 4.

Different formulas for density can be found also in [Sun et al., 2008], [Density of Carbon dioxide], [Calculation of density, enthalpy and entropy for supercritical carbon dioxide].

For the superior layer of the ocean salt water with the depth of $120 \mathrm{~m}$, the superior mean density is $\rho_{s}=1013.3 \mathrm{~kg} / \mathrm{m}^{3}$.

For the medium layer of the ocean salt water with the depth of $510 \mathrm{~m}$, the medium mean density is $\rho_{m}=1026.88 \mathrm{~kg} / \mathrm{m}^{3}$.

For the bottom layer of the ocean salt water with the depth of $3745 \mathrm{~m}$, to the end of the pipe, the bottom mean density is $\rho_{b}=1027.19 \mathrm{~kg} / \mathrm{m}^{3}$.

The liquid $\mathrm{CO}_{2}$ introduced in the pipe is a hydrate, a binary carbon dioxide clathrate. According to [Fer \& Haugan, 2003], it has a mean density of $\rho_{\mathrm{CO}_{2}}=1120 \mathrm{~kg} / \mathrm{m}^{3}$ at around $2^{\circ} \mathrm{C}$.

In formula (1) and (2), because we can substitute the variables densities with the mean densities for every zone, the pressures can be then calculated without using the integrals. They will be substituted with the product between the density, the gravitational acceleration and the corresponding depth.

The pressure exerted by the carbon dioxide clathrate from formula (1) becomes:

$p_{\text {pipe }, 2}=480.65 \mathrm{bar}$

The pressure exerted by the three layers of salt ocean water from formula (2) becomes:

$$
p_{\text {ext }, 2}=440.68 \mathrm{bar}
$$

The pressure difference between them, from formula (3), becomes:

$\Delta p \cong 40 b a r$

We chose for the pipe interior diameter the value of $1.2 \mathrm{~m}$, a value large enough to diminish the linear hydraulic losses and small enough to diminish the costs.

We also consider that the linear hydraulic losses coefficient $\lambda$ value is of 0.02 , because we chose to buy a new pipe. 
Substituting the numerical values obtained before, the carbon dioxide clathrate mean speed at the exit of the pipe from formula (5) becomes:

$$
v_{2}=3.09 \mathrm{~m} / \mathrm{s}
$$

The volumetric carbon dioxide clathrate rate flow from formula (6) becomes:

$$
Q=3.49 m^{3} / s
$$

We must then calculate the useful volume of the Ryukyu pit. Using the data from

Figure 2, the estimated surface of the pit is $S=27.381 \mathrm{~km}^{2}$. We must mention that the total surface of the pit is 2.5 times bigger than what can be seen between $129^{\circ}$ and $130^{\circ}$ longitude and between $25^{\circ}$ and $26^{\circ}$ latitude, as in Figure 2.

The mean depth in the interior of the useful volume of the Ryukyu pit under 4375 $\mathrm{m}$ is $h_{m}=1270.2 m$ and it was calculated as an arithmetic mean of all the depths available.

The useful volume of the Ryukyu pit is then $V=S \cdot h_{m}=34.775 \cdot 10^{12} \mathrm{~m}^{3}$.

Substituting the numerical values obtained before, the necessary time to fill the ocean pit with carbon dioxide clathrate in formula (7) becomes:

$$
T=2.77 \cdot 10^{9} \mathrm{~h}
$$

Roughly speaking this means more than 300,000 years.

\section{Conclusions}

We presented in this article a very useful perspective for the deposition of the liquid $\mathrm{CO}_{2}$ generated in the industrial processes in Asia.

The type of the deposit analyzed here as an example may be created under the depth of $4375 \mathrm{~m}$ in the Ryukyu pit near the shores of Japan. This is a concrete solution, effective to reduce global warming.

The authors proposed a general theoretical method based on the integral calculus employed to determine, in the end, the basic hydraulic values helpful in estimating the liquid $\mathrm{CO}_{2}$ deposition. This is followed by a numerical practical calculus, associated with the theoretical calculus, which contains the final numerical results regarding the carbon dioxide clathrate disposal at the bottom of the Ryukyu pit.

The authors obtained the mean speed at the exit of the carbon dioxide clathrate from the pipe, the volumetric carbon dioxide clathrate rate flow, the useful volume of the Ryukyu pit for the carbon dioxide clathrate deposition and the necessary time to fill the ocean pit with carbon dioxide clathrate.

Useful information about the characteristics of seas and oceans can be found for example in [Costello et al., 2010], [Hamlin, 2000], [Malt, 1994], [Petersen, 1994], [Schuster, 2003] and [Tomczak. \& Godfrey, 2003].

Utilizing the information and data offered by different authors [Gunther et al., 1996], [Baklid et al., 1996], [Fujioka et al., 1997], [Bachu et al., 1994], [Fer \& Haugan, 2003], [Smith \& Sandwell, 1997], [Millero et al., 1980], [Stangroom, 1995], [Zhao, 2000], [Oceanic provinces and zones], [GEBCO, 2015], an economical calculus can be made in the future.

We can choose any other position and other kind of pit and the structure of the calculus will be the same. Only different values for the densities and gravitational acceleration must be chosen, according to different layers of the salty water and different positions on the globe.

The impact in the energy world is commented in different type of papers as [Goldthorpe, 2017], [Smil, 2011] and [USAID, 2012].

Our approach is effective not only for stopping global warming but it has a good effect on the general economic system, as well. There are also other researchers 
preoccupied by the process of the $\mathrm{CO}_{2}$ capturing from the atmosphere who can agree with our "Operation Pitfall" as [Keith et al., 2018], [Bushuyev et al., 2018], [Wei et al., 2017], [Sunoda et al., 1998]. Such papers clearly indicate a global fervor to find economically useful processes to utilize carbon dioxide gas. This is intentionally removed from the air in order to stop any additional buildup of that greenhouse gas in Earth's atmosphere which leads to global warming. Anyway, there were researchers preoccupied by the problem of global warming long time ago as [Nordhaus, 1975], [Marchetti, 1977].

Therefore, the extraction from the air of the carbon dioxide gas, increasingly investigated by Green geo-engineers, as well as the globally and carefully planned deposition of that industrial product (liquidized gas) into pits located at depth on the ocean's floor is very useful. It is really a new kind of "natural" long or short-term material storage warehouse or, perhaps, a kind of artificial "oil pool" or "natural gas bubble". Many times, different liquid or gas materials are pumped underground, as, for example, by the USA national defense systems. Imported oil and natural gas are already, since Cold War days, artificially maintained in places such as State of Louisiana, USA. Drilling and later, extraction of oil and gas as well as injection of liquid waste underground for final disposal often causes earthquakes. The carbon dioxide clathrate deposition at the bottom of an ocean pit reduces these possibilities.

\section{References}

Bachu S., Gunter W.D., Perkins E.H. (1994) Energy Conversion and Management, ELSEVIER, 35, pg. 269-279.

Baklid A., Korbol R., Owren G. (1996) Society of Petroleum Engineers, SPE Annual Conference and Exhibition, SPE 36000-MS.

Bădescu V.; Ciocanea A.; Cathcart R.B., Finkl C.W. (2012) Desalination brine disposal by submerged pipes in Red Sea, Journal of Coastal Research, West Palm Beach (Florida), ISSN 0749-0208.

Bushuyev et al., (2018) "What Should We Make with $\mathrm{CO}_{2}$ and How Can We Make It?", JOULE 2: 1-8, 16 May 2018.

Calculation of density, enthalpy and entropy for supercritical carbon dioxide, Retrieved from http://www.criticalprocesses.com/Calculation\%20of\%20density, $\% 20$ enthalpy\%20and\%20entropy\%20of\%20carbon\%20dioxide.htm

Costello, M.J.; Cheung, A., and De Hauwere, N. (2010) Surface area and the seabed area, volume, depth, slope, and topographic variation for the world's seas, oceans, and countries. Environmental Science \& Technology, 44, 8821-8828.

Density of Carbon dioxide, Retrieved from http://www.ddbst.com/en/EED/PCP/DEN_C1050.php

Fer I., Haugan P. (2003) Limnology and Oceanography, 48(2), pg. 872-883.

Florea, J. and Panaitescu, V. (1979), Mecanica Fluidelor. Bucharest: Editura Didactică și Pedagogică, Didactical and Pedagogical Publishing House, 359 pg.

Fujioka Y., Ozaki M., Takeuchi Shindo K., Y., Herzog H. J. (1997) Energy Conversion and Management, ELSEVIER, 38, S273-S277.

Gatusso J.P., Magnan A., Bopp L., Cheung W., Duarte C., Hinkel J., Mcleod E., Micheli F., Oschlies A., Williamson P., Bille R., Chalastani V., Gates R., Irisson J. O., Mideelburg J., Portner H. O., Rau G. (2018) Ocean Solutions to Adress Climate Change and Its Effect on Marine Ecosystems, Frontiers in Marine Science, DOI: 10.3389/fmars. 2018.00337. 
The General Bathymetric Chart of the Oceans (GEBCO) Undersea Feature Names (2015) Gazetteer-GOTO: http://bit.ly/GEBCO-Gazetteer.

Goldthorpe S. (2017) Proc. of $13^{\text {th }}$ International Conference on Greenhouse Gas Control Technologies, Energy Procedia 114, pg. 5417-5429.

Google Earth software (ocean depth is presented as negative elevation at a selected location).

Gunter W.D., Bachu S., Law D.H.-S., Marwaha V., Drysdale D.L., Macdonald D.E., McCann T.J. (1996) Energy Conversion and Management, ELSEVIER, 37, 6-8, 1135-1142. A. Baklid, R. Korbol, G. Owren, Society of Petroleum Engineers, SPE Annual Conference and Exhibition, SPE 36600-MS.

Hamlin, C. (2000) 'Waters' or 'water'? - master narratives in water history and their implications for contemporary water policy. Water Policy, 2, pg. 313-325.

IEA (2015) Energy and Climate Change, World Energy Outlook Special Report.

IEAGHG (2000) report PH3/26 July 2000. Capture of $\mathrm{CO}_{2}$ using water scrubbing. IPCC (2005) IPCC Special Report on Carbon dioxide Capture and Storage-Chapter 6 Ocean Storage, Cambridge University Press, Retrieved from

https://www.ipcc.ch./publications_and_data/publications_and_data_reports.shtml\# Kawamura H., Yoon J-H., Ito T. (2007) Formation Rate of Water Masses in the Japan Sea, Journal of Oceanography, Vol. 63, pg. 243 to 253.

Keith et al., (2018) "A process for Capturing $\mathrm{CO}_{2}$ from the atmosphere", JOULE 2: 1-22, 15 August 2018.

Kim, K. and Chung J. Y. (1984) On the salinity minimum and dissolved oxygen maximum layer in the East Sea (Sea of Japan), pg. 56-66, Ocean Hydrodynamics of the Japan and East China Seas, Elsevier Oceanograph. Series, edited by T. Ichiye, Elsevier, New York.

Kim, K., Kim K. R., Kim Y. G., Cho Y. K., Chung J. Y., Choi B. H., Byun S. K., Hong G. H., Takematsu M., Yoon J. H., Volkov Y. and Danchenkov M. (1996) New findings from CREAMS observations: Water masses and eddies in the East Sea, J. Korean Soc. Oceanography, 31, pg. 155-163.

Kim, K., Kim K. R., Min D. H., Volkov Y., Yoon J. H. and Takematsu M. (2001): Warming and structural changes in the East Japan Sea: A clue to future changes in global oceans? Geophys. Res. Lett., 28, 17, pg. 3293-3296.

Malt, B.C. (1994) Water is not $\mathrm{H}_{2}$ O. Cognitive Psychology, 27, pg. 41-70.

Marchetti C. (1977) “On Geoengineering and the $\mathrm{CO}_{2}$ Problem”, Climate Change 1: 59-68.

Mândrea L. (2008) Fluid Mechanics, ISBN 978-973-0-05570-2.

Mândrea L., Bădescu V., Militaru G. (2018) The $\mathrm{CO}_{2}$ liquid disposal in sea pits near Greece, MATEC Web of Conferences, 07010, International Conference IManEE, Chișinău, 30.05-2.06.2018, 6 pg., Published online: 24 July 2018, DOI: https://doi.org/10.1051/matecconf/201817807010

Millero, F.; Chen, C.; Bradshaw, A., and Schleicher, K. (1980) A new high pressure equation of state for seawater. Deep Sea Research, part A, 27, pg. 255-264.

Minami, H., Kano Y. and Ogawa K. (1997): Long-term variation of Japan Sea Proper Water, J. Meteoro. Res., 49(4), pg. 97-106, in Japanese.

Miyazaki, M. (1953): On the water masses of the Japan Sea. Bull. Hokkaido Reg. Fish. Res. Lab., 7, 1-65 (in Japanese), Postlethwaite, C. F., E. J. Rohling, W. J. Jenkins and C. F. Walker (2005): A tracer study of ventilation in the Japan/East Sea. Deep-Sea Res. Part II, 52, pg. 1684-1704.

Nordhaus W.D. (1975), “Can We Control Carbon Dioxide?”, IIASA-Working Paper WP-75-63, June 1975. 
Oceanic provinces and zones, Retrieved from http://www.seafriends.org.nz/enviro/habitat/intro.htm

Petersen, U. (1994) Mining the hydrosphere. Geochimica et Cosmochimica Acta, 58, Pg. 2387-2403.

Schuster, L.A. (2003) Thinking deep. Civil Engineering, 73, pg. 46-53.

Senjyu, T. and H. Sudo (1996): Interannual variation of the upper portion of the Japan Sea Proper Water and its probable cause, J. Oceanogr., 52, pg. 27-42.

PICBE $\mid 297$

Smil, V. (2011) Global energy: the latest infatuations. American Scientist,99, pg.212-219.

Smith W.H.F., Sandwell D.T. (1997) Global Sea Floor Topography from Satellite Altimetry and Ship Depth Soundingss, Science 277, pg. 1956-1962 [see http://topex.ucsd.edu/marine_topo/mar_topo.html; at Scripps Institution of Oceanography, University of California, San Diego, 9500 Gilman Drive, La Jolla, 92093-0225; accessed: 21 September 2009].

Stangroom, J.E. (1995) A novel method of manipulating heavy loads underwater. In: Robinson, A.R. and Kupferman, S.L. (eds.). Man-Made Objects on the Seafloor: Discover, Investigation and Recovery. New York: Society for Underwater Technology, pg. 121-133.

Sudo, H. (1986): A note on the Japan Sea Proper Water, Prog.Oceanogr., 17, pg. 313-336.

Sun H., Feistel R., Koch M. and Markoe A., New equations for density, entropy, heat capacity, and potential temperature of a saline thermal fluid, Deep-Sea Research I 55, pg. $1304-1310,2008$.

Sunoda K. et al., (1998) “CO 2 Sea Bottom Throw-Away System”, US Patent 5,820,300 awarded 13 October 1998.

Tomczak., M. and Godfrey, J.S. (2003) Regional Oceanography: An Introduction. Delhi: Daya Publishing House, pg. 215-219.

USAID (U.S. Agency for International Development), (2012). Global scan of world energy trends. http://www.sari-energy.org/pagefiles/what_we_do/activities/ gemtp/cee-global_scan.pdf (accessed February 2, 2012).

Zhao J. (2000) Diffusion, Costs and Learning in the Development of International Gas Transmission Lines. Laxenburg, Austria: International Institute for Applied Systems Analysis IIASA interim report IR-00-054. http: www.iiasa.ac.at/ Admin/PUB/Documents/IR-00-054.pdf (accessed February 2, 2012).

Yasui, M., Yasuoka T. and Shiota 0. (1967): Oceanographic studies of the Japan Sea Water characteristics, Oceanogr.Mag., 19, pg. 177-192.

Wei et al. (2017), "Directly converting $\mathrm{CO}_{2}$ into a gasoline fuel" $N A T U R E$ COMMUNICATIONS 8: 15174. 